DIEGO SALINAS FLORES

SANTIAGO, CHILE

HOLA@DGOSALINAS.CL

\title{
Mareas Educativas / Movilizaciones Globales
}

\author{
Revolutionary Tides in Education / \\ Global Mobilizations
}

1. A propósito de esto, el proyecto Mapa Teatro estuvo expuesto hasta finales del mes de abril del 2019, donde articuló una serie de elementos textuales, gráficos, audiovisuales y de montaje sobre la relación histórica del museo con la colonización de América, cuyo edificio fuera previamente el Hospital General y de la Pasión de Madrid. 2. Revisar Huyssen, A. (2000). "En búsqueda del tiempo futuro". En Revista Puentes año 1 no.2, 9.
Cómo citar: Salinas Flores, D. (2019)

Mareas Educativas / Movilizaciones Globales. RChD: creación y pensamiento, 4(6), 1-5 DoI: $10.5354 / 0719-837 \times .2019 .53638$
Si bien este texto partió estructurado como una reseña, terminó como un texto que permite el cierre del primer proceso de constitución de obra en base a la memoria y el archivo fotográfico y audiovisual del Colectivo FAUNA sobre la movilización estudiantil del año 2011 en Santiago. También es una reflexión, y a ratos crítica, sobre la forma en que compartimos y consumimos la producción cultural en esta sociedad neoliberal, que toma como punto de partida la invitación que me realiza el Museo Nacional Centro de Arte Reina Sofía a exponer sobre el movimiento del 2011 a finales de febrero del año 2019. Finalmente, es un texto que se construye y considera los movimientos sociales de los últimos años y el cómo pensar su archivo, no como un final sino un futuro para las siguientes mareas que vendrán.

La actividad en sí suponía afrontar algunas contradicciones propias de la invitación y su origen: llegar a relatar la experiencia del movimiento social de 2011 en un contexto distinto al usual, ya que el público/lector es esa ciudadanía que no fue parte ni tuvo (ni tiene) mayor noticia de los problemas sociales de nuestro continente. $Y$ sobre todo, el conflicto de presentar un análisis sobre el estado político, social y cultural ante la tribuna de los colonizadores y en un espacio construido gracias a los tributos de las indias ${ }^{1}$. La escritura de esta reseña no puede pasar por alto dichos cuestionamientos, ni tampoco en el peligro instalado en las sociedades occidentales contemporánea de la museificación de la memoria o “memorialización” como estrategia para contrarrestar el miedo al olvido², y particularmente en este caso, la institucionalización de la protesta y los conflictos sociales que al museo le ha resultado cautivante estos últimos años.

Otro de los supuestos que debo dejar claro acerca de mi intervención en el Museo Reina Sofía es el propio proyecto de archivo del que toma sustento y origen la conferencia realizada. Si bien éste se construye a partir de la sistematización, ordenación y razonamiento de una muestra de fotografías capturadas durante las movilizaciones estudiantiles del año 2011, hay que entenderlo como un proyecto autoral, donde la visión del fotógrafo queda plasmada no solo al momento de la captura, sino también en la selección propia del archivero. El ejercicio de considerar las imágenes para una reconstrucción historicista del movimiento recae en el vicio no menor de pensarlas como un instrumento objetivo en la búsqueda de la verdad, como susceptibles de una sola y única lectura. Al contrario, este proyecto se erige bajo el concepto de la resignificación que le pueden dar los lectores a las imágenes, a la creación de obra derivada y a las diversas lecturas políticas que emerjan de dicha acción. Así, la obra se completa con las propias vivencias del espectador, cuya posición se intercambia constantemente entre la contemplación y la participación, para tomar el rol de intérpretes activos que construyen su propio lenguaje para "apropiarse de la historia y hacer de ella su propia historia" (Rancière, 2010, p 19).
Revista Chilena de Diseño,

RChD: creación y pensamiento

Universidad de Chile

2019, 4(6)

http://rchd.uchile.cl 
3. La primera fase del Archivo Colectivo FAUNA consideró la creación de un archivo web y la activación mediante una instalación de envío postal en la Federación de Estudiantes de la Universidad de Chile.

4. Mayor información respecto a la actividad puede encontrarse en el sitio web del Museo Reina Sofía https://www.museoreinasofia.es/ actividades/mareas-educativas-movilizacionesglobales-defensa-educacion-publica
Por último, aparece otro lado de la cuestión de la autoría como parte de las características propias de las imágenes, cuyo contenido aborda la producción de diversas manifestaciones creativas realizadas en la Facultad de Arquitectura y Urbanismo durante las movilizaciones. Cuestión que para la instancia de la exposición en Madrid se quiso potenciar durante la conferencia, en el entendido que mi autoría es parcial y se diluye al momento de analizar el contenido mismo de las fotografías. Para esto, consideré trabajar con el archivo audiovisual, el cual no había sido utilizado para la primera fase del proyecto ${ }^{3}$, y realicé finalmente un video-ensayo de carácter documental, introduje tres voces participantes de las movilizaciones que abordaron temáticas como la archivación de la memoria, la creación colectiva y otros cuestionamientos afines que permitieron nutrir con lecturas distintas del periodo y del proyecto.

\section{II}

La conferencia "Mareas educativas: movilizaciones globales en defensa de la educación pública" 4 fue parte del grupo de la "Escuela de la Escucha" de la Escuela Perturbable, y se realizó así el 21 de febrero, en el auditorio del Edificio Sabatini del Museo Reina Sofía. Tuvo de invitado al profesor, activista y actual representante del movimiento Marea Verde, Agustín Moreno, además de mi participación. De aquí en más, se deben precisar ciertos detalles contextuales respecto a la organización y la actividad:

A. El proyecto de la Escuela Perturbable tuvo por eje principal la educación artística como práctica emancipadora en las sociedades contemporáneas. Transcurrió en paralelo a la exposición "Hospicio de utopías fallidas", de Luis Camnitzer, retrospección del artista conceptual uruguayo cuya práctica se destaca por su crítica al arte-mercancía (y extenderla hacia la realidad social) y al rol del artista-creador en las sociedades de consumo/neoliberales, donde hace partícipe activamente al espectador en sus obras y su proceso.

B. Fueron tres grandes grupos con los que se abordaron cuestionamientos sobre la relación entre arte y educación: la "Escuela de la Escucha", donde se trabajaron las ideas de Camnitzer junto con profesores de educación básica y secundaria, y la manera en que se ha relegado el espacio de la educación artística en las aulas a algo casi anecdótico; el grupo “480+20", conformado por un grupo heterogéneo de artistas, estudiantes, profesores y ciudadanos que se reunieron a conversar sobre el aprendizaje de los artistas en la universidad. Por último, el grupo "Situar la mediación", que tomó como punto de reflexión las prácticas de mediación en los museos, y la relación entre la educación, lo artístico y lo curatorial.

C. El concepto de "marea", al que se hace referencia en el título de la actividad, es utilizado por los españoles para referirse al espacio social y político, derivado de las grandes movilizaciones en Madrid conocidas como el 15M, cuya actividad está orientada hacia la recuperación o defensa de algún derecho social. Ejemplos de este tipo de grupos hay varios, la "marea verde" uno de las más grandes y que ha perdurado en el tiempo, cuya lucha está orientada a la defensa de las escuelas públicas y los derechos universales asociados a la educación. 
La conferencia se realizó con un público principalmente de profesores de escuelas públicas y participantes de la "marea verde", con los cuales se dio una enriquecedora conversación sobre los problemas de los sistemas educativos, tanto español como chileno, donde destacaron las variadas similitudes y formas de operar del poder político para debilitar la educación pública e intentar perpetuar las diferencias y reforzar los privilegios de los que ya los tienen.

La exposición de Agustín Moreno fue bastante clara respecto del estado del sistema educacional de Madrid y la región, así como del contexto global si pensamos en el cambio histórico que ha supuesto la expansión del neoliberalismo como proyecto económico y político a nivel global, mediante estrategias similares a la coerción militar (teniendo de ejemplo las dictaduras del cono sur en América), la coerción financiera y mediante lo que Moreno denominó la "construcción del consentimiento"; o aquellos mecanismos que permiten mantener el statu quo, donde la educación ocupa un rol fundamental.

Las estrategias de debilitamiento de la educación pública en España tomaron tres vías principales: los recortes financieros aplicados; a través de los intentos de privatización de escuelas y centros educativos y, por último, mediante normativas y leyes que profundizan la desigualdad y la segregación. Son variadas las similitudes respecto de lo relatado por Agustín Moreno con la realidad del sistema educacional chileno, aunque la privatización de la enseñanza en nuestro país ha calado mucho más hondo respecto de su par español. De allí, que quizás pueda entenderse otra de las grandes diferencias respecto de los dos movimientos por la educación que han emergido a lo largo de la década, y es que en el caso de la Comunidad de Madrid es el profesorado y profesionales de la educación quienes emergen como sujeto y actor principal en la defensa de la educación pública (con el apoyo del estamento estudiantil y de la sociedad civil), a diferencia de lo que se puede apreciar en el caso chileno, donde el actor que emerge y marca la pauta política es el estamento estudiantil. No obstante las diferencias, se coincide en la conformación de resistencias desde el año 2011 en adelante, que intentan combatir y frenar las reformas neoliberales en pos de una educación pública de calidad, universal, gratuita y de titularidad, como señaló Moreno en su exposición.

En cuanto a mi intervención, expuse un resumen de las falencias del sistema educacional chileno, con énfasis en cuatro problemas principales: la calidad impartida en los establecimientos o instituciones de educación, la segregación y la inequidad, la propia institucionalidad que regula el sistema; y por último, los problemas en la formación y calidad de los docentes. Esto, contemplando como hilo conductor las grandes reformas neoliberales implantadas a la fuerza desde la dictadura cívico-militar, como la adopción del sistema voucher y la atomización de las universidades estatales desde la reforma constitucional de la década de 1980, para pasar por el asentamiento de los mecanismos durante los gobiernos de la Concertación y cómo terminaron por surgir las resistencias, específicamente durante los años 2006 y 2011. Aproveché la relación entre los conceptos de arte y educación, para enfocar la conversación hacia la manera en que se adoptaron diversas formas de protesta creativa y de recuperación del espacio público, al pensar en el año 2011 como punto de análisis y de contexto. Esto me permitió realizar una 
5. Esto como reacción a la frase de Von Baer en contra del aborto terapéutico; "una mujer que presta el cuerpo en el fondo". Podríamos vincular, la en ese entonces forma de protesta, con la ahora repudiada "broma" el 2016 a Luis Céspedes, ministro de Economía de Michelle Bachelet, a quien durante la reunión de Asexma le regalaron una muñeca inflable breve reseña del proyecto de archivo, y presentar el video-ensayo como pase a la segunda fase y debate sobre los diversos aprendizajes que dejaron las movilizaciones y cuáles eran las proyecciones hacia el futuro.

\section{III}

La conferencia se tornó hacia una conversación marcada por las preguntas sobre el estado actual de las movilizaciones, junto con aventurar un panorama futuro al respecto. Al menos en el caso chileno, la evolución del "movimiento estudiantil" ha sido variada en cuanto a los aprendizajes como a los efectos que tuvo desde el año 2011, no solo de una transferencia de conocimiento en el propio gremio, sino en la forma de hacer y ver la política; con el Frente Amplio como uno de los grandes ejemplos de nuevas formas que derivan del trabajo político que se asienta a principios de esta década.

Ahora bien, es imposible dejar fuera los aprendizajes que provienen desde otros sectores y la manera en que permearon y fueron enriqueciendo las propias demandas de los movimientos estudiantiles de cada año, como lo fueron la integración de la educación cívica dentro de los programas (haciéndose cargo de la participación política de los jóvenes), las demandas por mayor integración de las minorías, como migrantes y las diversidades sexuales. Destaca sobre todo en los últimos cinco años la conjunción con las demandas de los movimientos feministas que han surgido en la última década, con demandas de una educación no sexista, las diversas tomas y movilizaciones contra los casos de acoso y abuso en distintas universidades y establecimientos educacionales chilenos, así conforme el paulatino fin de los colegios monogenéricos como parte de los últimos debates.

Al hacer un rápido ejercicio de análisis respecto del archivo del año 2011 hacia el futuro, es evidente cierto cambio en las prácticas discursivas en las diversas manifestaciones e intervenciones en el espacio público, de las formas de utilización del cuerpo como parte de la protesta y otras tantas, al igual que los mismos cantos vociferados por los estudiantes durante las marchas donde han ido desapareciendo algunos gritos derechamente transfóbicos o sexualizantes, o que sería difícil ver en la actualidad una muñeca inflable con la cara de Ena Von Baer5.

Respecto al concepto de marea, analogarlo con la recurrencia del fenómeno natural hace pensar que, así como sube, debería bajar, o que volverá a aparecer nuevamente y esto supone un riesgo. Los movimientos sociales son bastante dinámicos y tienen diversas dimensiones o tipologías: los que tienen por objeto la constitución de un sujeto; la instrumental, que tiene por objeto una demanda concreta; la política, que apunta a la transformación de la sociedad o de un ámbito de ella. El mismo movimiento (Quirosa, Rafael \& Muñoz, 2011) estudiantil chileno no puede entenderse como un continuo, sino una multiplicidad de movimientos caracterizados por sus demandas, el contexto histórico, su relación con el poder, su propia politicidad o su carácter gremial, y la exigencia de sostener este supuesto continuo ha hecho evidente una suerte de desmemoria, quiebres en el propio conocimiento del movimiento estudiantil por parte de sus actores.

Por último, y si seguimos con la analogía, la marea que vuelve no es siempre la misma, tanto por el agua que viaja ni la roca donde golpea. De allí que la 
voluntad de registro, de archivo y resignificación de las acciones de protesta puede permitir una mejor transmisión de los conocimientos y de los aprendizajes del movimiento social, de forma de resistir de mejor manera los embates neoliberales y conservadores de estos últimos años, sobre todo como los que atentan contra las memorias y los movimientos sociales. "Acumular imágenes es una forma de la memoria, volverlas disponibles es necesario para desbrozar la huella por la que seguir andando"(Carri, 2010), es considerar al archivo como forma de resistencia, y sobre todo como punto de origen de algo más, de las decisiones sobre cuáles formas ya no funcionaron y cuáles cambiar y/o transformar, como origen de la observación y ejecución de nuevas obras, de nuevas lecturas políticas y nuevas críticas en orden de la construcción del futuro más que por seguir en la saudade por el pasado.

\section{Referencias}

Carri, Albertina. (2010). Restos [Corto cinematográfico]. País: Argentina.

Quirosa, Rafael \& Muñoz (Eds.). (2011). “Movilizaciones

y movimiento social en la democratización política chilena". En La sociedad española en la Transición.

Madrid: Biblioteca nueva.

Rancière, Jacques. (2010). El espectador emancipado.

España: Ellago Ediciones. 